\title{
Mechanical Properties of Nanohybrid Resin Composites Containing Various Mass Fractions of Modified Zirconia Particles
}

This article was published in the following Dove Press journal: International Journal of Nanomedicine

\author{
Gaoying Hong $\mathbb{D}^{\prime}$ \\ Jiaxue Yang $\mathbb{D}^{\prime}$ \\ Xin Jin ${ }^{2}$ \\ Tong Wu $\mathbb{D}^{\prime}$ \\ Shiqi Dai $\mathbb{1}^{\prime}$ \\ Haifeng Xie (D) \\ Chen Chen ${ }^{2}$
}

'Jiangsu Key Laboratory of Oral Diseases, Department of Prosthodontics, Affiliated Hospital of Stomatology, Nanjing Medical University, Nanjing, People's Republic of China; ${ }^{2}$ Jiangsu Key Laboratory of Oral Diseases, Department of Endodontics, Affiliated Hospital of Stomatology, Nanjing Medical University, Nanjing, People's Republic of China
Correspondence: Chen Chen; Haifeng Xie

Han-Zhong Road 136th,

Affiliated Hospital of Stomatology,

Nanjing Medical University, Nanjing

210029 , People's Republic of China

$\mathrm{Tel}+862569593031$; +86256959308I

Fax+8625865I 64I4

Email ccchicy@njmu.edu.cn;

xhf-1980@I26.com
Purpose: The aim of this study was to investigate the effect of various mass fractions of 10methacry-loyloxydecyl dihydrogen phosphate (MDP)-conditioned or unconditioned zirconia nano- or micro-particles with different initiator systems on the mechanical properties of nanohybrid resin composites.

Methods: Both light-cured (L) and dual-cured (D) resin composites were prepared. When the mass fraction of the nano- or micro-zirconia fillers reached $55 \mathrm{wt} \%$, resin composites were equipped with dual-cured initiator systems. We measured the three-point bendingstrength, elastic modulus, Weibull modulus and translucency parameter of the nanohybrid resin composites containing various mass fractions of MDP-conditioned or unconditioned zirconia nano- or micro-particles $(0 \%, 5 \mathrm{wt} \%, 10 \mathrm{wt} \%, 20 \mathrm{wt} \%, 30 \mathrm{wt} \%$ and $55 \mathrm{wt} \%)$. A Cell Counting Kit (CCK)-8 was used to test the cell cytotoxicity of the experimental resin composites. The zirconia nano- or micro-particles with MDP-conditioning or not were characterized by transmission electron microscopy (TEM), Fourier infrared spectroscopy (FTIR), and X-ray photoelectron spectroscopy (XPS).

Results: Resin composites containing 5-20 wt\% MDP-conditioned or unconditioned nanozirconia fillers exhibited better three-point bending-strength than the control group without zirconia fillers. Nano- or micro-zirconia fillers decreased the translucence of the nanohybrid resin composites. According to the cytotoxicity classification, all of the nano- or microzirconia fillers containing experimental resin composites were considered to have no significant cell cytotoxicity. The FTIR spectra of the conditioned nano- or micro-fillers showed new absorption bands at $1719 \mathrm{~cm}^{-1}$ and $1637 \mathrm{~cm}^{-1}$, indicating the successful combination of MDP and zirconia particles. The XPS analysis measured $\mathrm{Zr}-\mathrm{O}-\mathrm{P}$ peak area on MDPconditioned nano- and micro-zirconia fillers at $39.91 \%$ and $34.89 \%$, respectively.

Conclusion: Nano-zirconia filler improved the mechanical properties of nanohybrid resin composites, but cannot be the main filler to replace silica filler. The experimental dual-cured composites can be resin cements with better opacity effects and a low viscosity.

Keywords: resin composite, nano-zirconia filler, MDP, initiator system, mechanical property, translucence

\section{Introduction}

Resin composites are currently the preferred materials for both direct and indirect dental restorations, but have a higher failure rate than traditional amalgam for posterior restorations in long-term studies, ${ }^{1,2}$ This can lead to the fracture of the inner resin restorations and is the main reason for clinical failure. ${ }^{3,4}$ Further improvements in the mechanical properties of dental resin composites remain a concern. 
Fillers are responsible for most of the mechanical properties of the resin restorations. ${ }^{5}$ Consequently, current studies are usually devoted to developing and optimizing fillers, including the filler type (silica, zirconia, hydroxyapatite), size, and shape..$^{5-7}$ The size of the particles initially added to the resin composites are distributed from 10 to 50 $\mu \mathrm{m}$, and fillers of this type are defined macrofillers. Microfilled and hybrid composites appear with a decreasing size and widening size distribution of the particles. ${ }^{8}$

The introduction of nanotechnology is a recent development in the field of composite resin materials, including nanofilled and nanohybrid resin composites. ${ }^{9}$ Nanohybrid resin composites are the most popular, because they improve the distribution of fillers in the matrix by combining nanoparticles with submicron particles to achieve better mechanical, chemical, and optical properties. ${ }^{10-12}$ Studies on nano- or nanohybrid-fillers still focus on silica fillers. Silica particles are the first fillers used because of their appropriate refractive index, low cost, easy synthesis, simple modification, high strength and good elastic modulus when added to resins. ${ }^{5,13,14}$ However, in pursuit of the mechanical properties of resin composites to improve the long-term success rate in posterior restoration, researchers and manufacturers have focused on zirconia particles. Nano-zirconia particles have been added to resin composites as reinforcing or toughening components due to their unparalleled mechanical strength. ${ }^{15,16}$ They show effectiveness at enhancing flexural strength and wear resistance. ${ }^{17,18}$

However, surface treatment of inorganic fillers can improve the dispersion of the fillers in the matrix and strengthen the combination of the fillers and the matrix. The chemical bonds with the resin matrix need to be strengthened because inorganic fillers fail to form chemical bonds with an organic resin matrix at the microscopic level. ${ }^{19}$ The nanohybrid resin composites require a surface treatment to prevent a significant agglomeration in the nanoparticles. ${ }^{20}$ The silanization of silica is a conventional step to promote its combination with the resin matrix while the current surface modification of zirconia remains immature. ${ }^{21}$ The phosphate ester monomer (MDP) can condition zirconia ceramic restorations as a functional monomer to achieve chemical bonds with resin cement. ${ }^{22-24}$ Recent studies confirmed that Bis-GMA and UDMA resin composites with a bit MDP-conditioned nano-zirconia fillers could obtain superior flexural strength, elastic modulus and surface hardness in vitro, versus resin composites with unconditioned zirconia fillers. ${ }^{17,18,25}$ This surface treatment similar to the silanization of silica fillers can lead to nano- or micro-zirconia fillers as the main fillers of resin composites.

However, the translucence and refractive index of zirconia particles are not desirable compared with those features of silica particles. ${ }^{17,26}$ It remains unclear whether the translucence of the resin would be affected as the nano-zirconia filler content increases. Moreover, resin materials with low translucence and a high refractive index are insufficiently cured by a light-cured initiator system. ${ }^{27}$ Consequently, an appropriate initiator system must be used to allow for acceptable polymerization kinetics and conversions in opaque resin materials.

This study investigated the effect of various mass fractions of MDP-conditioned or unconditioned zirconia nanoor micro-particles with different initiator systems on the mechanical properties of Bis-GMA-based nanohybrid resin composites. We then analyzed the possibility of zirconia nano- or micro-particles as the main fillers that replaced silica particles. The null hypotheses were that nano- or microzirconia fillers would not improve the mechanical properties of Bis-GMA-based resin composites, regardless of the mass fractions (i); 10-MDP conditioned zirconia fillers would not influence the mechanical properties of the materials (ii); moreover, initiator systems would not influence the mechanical properties of Bis-GMA-based resin composites containing zirconia nano- or micro-particles (iii).

\section{Methods}

\section{Study Design and Materials Tested}

In this in vitro study, 34 light-cured (L) and dual-cured (D) nanohybrid resin composites were designed according to Table 1 to evaluate the flexural strength, translucence and cytotoxicity, as the total mass fraction of fillers was $60 \mathrm{wt} \%$. The fillers were composed of micro-silica and nano-zirconia ( $0 \mathrm{wt} \%, 5 \mathrm{wt} \%, 10 \mathrm{wt} \%, 20 \mathrm{wt} \%$ and $30 \mathrm{wt} \%$ ) particles with silica as the main filler, or nano-silica and microzirconia (40 wt $\%, 50 \mathrm{wt} \%, 55 \mathrm{wt} \%$ and $60 \mathrm{wt} \%$ ) particles with zirconia as the main filler, wherein silica fillers were all conditioned with 3-methacryloxypropyltrimethoxysilane $(\gamma$-MPS). Morphological observation, Fourier transform infrared spectroscopy (FTIR) analysis and X-ray photoelectron spectroscopy (XPS) analysis were performed on the MDP-conditioned zirconia particles.

\section{Surface Treatments and Morphological Observations of Zirconia and Silica Fillers} MDP primer was prepared with the following formulation: ${ }^{18}$ $10 \mathrm{wt} \% \mathrm{MDP}, 88.8 \mathrm{wt} \%$ ethanol, $0.3 \mathrm{wt} \%$ camphorquinone 
Table I Groups According to Different Mass Fractions of MDP-Conditioned or Unconditioned Zirconia Nano- or Micro-Particles $(\mathrm{Wt} \%)$

\begin{tabular}{|c|c|c|c|c|c|c|}
\hline & \multicolumn{2}{|c|}{ Conditioned with $\gamma$-MPS } & \multicolumn{2}{|c|}{ Unconditioned } & \multicolumn{2}{|c|}{ Conditioned with MDP } \\
\hline & $\begin{array}{l}\text { Micro-Silica } \\
\text { Fillers }\end{array}$ & Nano-Silica Fillers & $\begin{array}{l}\text { Micro- } \\
\text { Zirconia } \\
\text { Fillers }\end{array}$ & $\begin{array}{l}\text { Nano- } \\
\text { Zirconia } \\
\text { Fillers }\end{array}$ & $\begin{array}{l}\text { Micro- } \\
\text { Zirconia } \\
\text { Fillers }\end{array}$ & $\begin{array}{l}\text { Nano- } \\
\text { Zirconia } \\
\text { Fillers }\end{array}$ \\
\hline 60si & 60 & & & & & \\
\hline $55 s i+5 z r$ & 55 & & & 5 & & \\
\hline $55 s i+5 \mathrm{Mzr}$ & 55 & & & & & 5 \\
\hline $50 s i+10 z r$ & 50 & & & 10 & & \\
\hline $50 \mathrm{si}+10 \mathrm{Mzr}$ & 40 & & & & & 10 \\
\hline $40 \mathrm{si}+20 \mathrm{zr}$ & 50 & & & 20 & & \\
\hline $40 \mathrm{si}+20 \mathrm{Mzr}$ & 40 & & & & & 20 \\
\hline $30 \mathrm{si}+30 \mathrm{zr}$ & 30 & & & 30 & & \\
\hline 30si+30Mzr & 30 & & & & & 30 \\
\hline $20 \mathrm{si}+40 \mathrm{zr}$ & & 20 & 40 & & & \\
\hline $20 \mathrm{si}+40 \mathrm{Mzr}$ & & 20 & & & 40 & \\
\hline $10 \mathrm{si}+50 \mathrm{zr}$ & & 10 & 50 & & & \\
\hline $10 \mathrm{si}+50 \mathrm{Mzr}$ & & 10 & & & 50 & \\
\hline $5 s i+55 z r$ & & 5 & 55 & & & \\
\hline $5 s i+55 M z r$ & & 5 & & & 55 & \\
\hline $60 \mathrm{zr}$ & & & 60 & & & \\
\hline $60 \mathrm{Mzr}$ & & & & & 60 & \\
\hline
\end{tabular}

Note: The size of the main filler is measured in microns, and that of the auxiliary filler in nanometers.

(Aladdin, China) and $0.9 \mathrm{wt} \%$ 4-dimethylamino-benzoic acid ethyl ester (EDMAB) (Aladdin, China). Nano- and micro-zirconia particles (Ruiteng Alloy Materials Co., Ltd., China) were immersed in the MDP primer at a concentration of $1 \mathrm{~g} / \mathrm{mL}$ and then dispersed ultrasonically for $10 \mathrm{~min}$ for a complete reaction. After storage for $12 \mathrm{~h}$ in the dark, the reaction mixture was filtered and rinsed three times with ethanol to remove excess unreacted MDP. Treated fillers were then centrifuged for $10 \mathrm{~min}$ and dried in an oven at $65^{\circ} \mathrm{C}$.

The $\gamma$-MPS primer was prepared with the following formulation: ${ }^{28} \gamma$-MPS (Macklin, China) $0.5 \mathrm{~g}$, cyclohexane (Sinopharm, China) $100 \mathrm{~mL}$, and propylamine (Sinopharm, China) 0.1 g. Both nano- and micro-silica particles were immersed in $\gamma$-MPS primer at a concentration of $5 \mathrm{~g} / 100$ $\mathrm{mL}$, following by stirring at room temperature for 30 minutes and then at $65^{\circ} \mathrm{C}$ until the solvent volatilized. Finally, the powder was dried in an oven at $65^{\circ} \mathrm{C}$.

Nano- and micro-zirconia particles and nano- and micro-silica particles were individually observed by TEM (Tecnai 12, Philips Corp., Netherlands) and SEM (MAIA3 TESCAN, Czech Republic).

\section{Characterization of MDP-Conditioned Zirconia Filler by Fourier Transform Infrared Spectroscopy (FTIR) and X-Ray Photoelectron Spectroscopy (XPS)}

FTIR (Nicolet 6700, Thermo Scientific, USA) was used to detect the modification of the MDP-conditioned zirconia powder. The powder was mixed with $\mathrm{KBr}$ under pressure, and FTIR analysis was performed in transmission mode in the range of $3500-500 \mathrm{~cm}^{-1}$. The free $\mathrm{P}-\mathrm{O}$ bond stretching vibration normally occurs in the range of $1200-950 \mathrm{~cm}^{-1}$, and peak separation processing was carried out in that range using Peakfit 4.12 software. Unconditioned zirconia was employed as a control.

The efficacy of the functionalization procedure was also assessed by XPS (Escalab 250xi, Thermo Fisher Scientific, UK) with monochromatic $\mathrm{A} 1 \mathrm{~K} \alpha$ radiation (photoenergy $=1486.6 \mathrm{eV}$, energy step size $=0.05 \mathrm{eV}$ ). The O1s spectra were processed using XPS Peak 4.1 software with the Lorentz-Gauss ratio fixed at $80 \%$. The relative content of surface chemical bonds $(\mathrm{Zr}-\mathrm{O}-\mathrm{P})$ was determined according to the peak area. 


\section{Preparation of Experimental Resin Composites}

Bisphenol A-diglycidyl methacrylate (Aladdin, China) and triethylene glycol dimethacrylate (Aladdin, China) were used as the resin matrix. The light-cured (L) and dualcured (D) resin composites were formulated according to Table 1.

The light-cured groups configured the single-paste resin composites. Its components were Bis-GMA:TEGDMA (7:3 ratio) co-monomer, camphorquinone $(0.5 \mathrm{wt} \%)$ as the photosensitizer, and dimethyl-p-toluidine (1 wt $\%)$ as co-initiator. ${ }^{18}$

The dual-cured groups configured two resin pastes containing the following ingredients: ${ }^{29}$

The base paste was Bis-GMA:TEGDMA (7:3 ratio) co-monomer, camphorquinone $(0.5 \mathrm{wt} \%)$ as the photosensitizer, and dimethyl-p-toluidine $(1 \mathrm{wt} \%)$ as the co-initiator. The catalyst paste was Bis-GMA:TEGDMA (7:3 ratio) co-monomer and benzoyl peroxide $(0.5 \mathrm{wt} \%)$ as self-polymerization promoter.

Nevertheless, resin materials in the total of 14 groups (L-20si+40zr, L-20si+40Mzr, L-10si+50zr, L-10si+50Mzr, L-5si+55zr, L-5si+55Mzr, L-60zr, L-60Mzr, D-20si+40zr, D-20si+40Mzr, D-10si+50zr, D-10si+50Mzr, D-60zr and D-60Mzr) cannot be molded successfully and did not submit to evaluate the three-point bending strength, translucence and cytotoxicity.

\section{Scanning Electron Microscopy (SEM) and Energy-Dispersive Spectrometry (EDS)}

\section{Mapping}

Each group of cured resin was polished flat with 1000-, 2000-, 3000-, and 4000-grit SiC papers, ultrasonically washed in water for $10 \mathrm{~min}$, and dried. The samples were then coated with gold and examined by SEM (MAIA3 TESCAN, Czech Republic) at an accelerating voltage of $15 \mathrm{kV}$ in backscattering electron mode. The EDS maps were collected to reveal the elemental distributions $(\mathrm{Si} / \mathrm{Zr} / \mathrm{O} / \mathrm{P} /)$ within the resin composites.

\section{Three-Point Bending Strength, Elastic Modulus, and Weibull Analysis}

According to ISO 4049, each group of resin was formed respectively in silicone molds $\left(2 \times 2 \times 25 \mathrm{~mm}^{3}\right)$ covered with Mylar film to reduce the effects of oxygen inhibition. They were then pressed by a glass plate to remove excess resin. The resin composites then were light-cured for $20 \mathrm{~s}$ on both sides. The test specimens were carefully removed from the mold, measured by electronic calipers and then polished flat. The error range of the final thickness of specimens was limited within $0.1 \mathrm{~mm}$. Each group of resins included 15 samples. These were then stored in a thermostatic water bath at $37^{\circ} \mathrm{C}$ for $24 \mathrm{~h}$ while avoiding light. Subsequently, the three-point bending strengths of the specimens with a bracket spacing of $20 \mathrm{~mm}$ were evaluated using a universal testing machine at a crosshead speed of $0.5 \mathrm{~mm} / \mathrm{min}$ until failure. The elastic modulus values of specimens were recorded directly in the software connected to the universal testing machine (3365 ElectroPuls; Instron, USA). The three-point bending strength $(\sigma)$ was calculated as $\sigma_{\mathrm{f}}=3 \mathrm{Fl} / 2 \mathrm{bh}^{2}$, where $\mathrm{F}$ is the maximum load $(\mathrm{N})$ exerted on the specimen, 1 is the distance $(\mathrm{mm})$ between the supports, $\mathrm{b}$ is the width $(\mathrm{mm})$, and $\mathrm{h}$ is the thickness $(\mathrm{mm})$. Based on the three-point bending strength $\left(\sigma_{f}\right)$ of the data, the failure probability $\left(\mathrm{P}_{\mathrm{f}}\right)$ was evaluated by Weibull analysis using the following formula: $\mathrm{P}_{\mathrm{f}}=1-\exp \left\{-\left(\frac{\sigma_{f}}{\sigma_{\theta}}\right)^{m}\right\}$, where $\sigma_{\mathrm{f}}$ is the bending strength, $\sigma_{\theta}$ is the scale parameter, and $\mathrm{m}$ is the Weibull modulus. The probability of failure may be estimated from the following formula: $\mathrm{P}_{\mathrm{f}}=(\mathrm{i}-0.5) / \mathrm{N}$, where $\mathrm{i}$ is the strength ranking arranged in ascending order, and $\mathrm{N}$ is the number of specimens. The Weibull modulus $(\mathrm{m})$ is a measure of the variability in the results and is determined by linear regression using the least-squares method as follows: $\ln \ln \frac{1}{1-\mathrm{P}_{\mathrm{f}}}=\mathrm{m} \ln \sigma_{\mathrm{f}}-\mathrm{m} \ln \sigma_{\theta}$, where the slope gives $m$, and $m \ln \sigma_{\theta}$ is the intercept.

\section{Translucency Parameter}

Each group of resin composite samples $(n=10$, diameter $6 \mathrm{~mm}$, thickness $1.5 \mathrm{~mm}$ ) was prepared (Table 1). We subsequently used a dental colorimeter (ShadeEye NCC; Shofu, Japan) to measure the color parameters of each sample under a black background $\left(\mathrm{L}^{*}=27.83, \mathrm{a}^{*}=-0.48, \mathrm{~b}^{*}=-0.98\right)$ and white background $\left(\mathrm{L}^{*}=94.64, \mathrm{a}^{*}=0, \mathrm{~b}^{*}=1.48\right)$ according to CIEDE2000 color space. The experiment was performed under the D65 standard illuminant. The instrument was calibrated before the test. A CIEDE2000 color difference between groups was calculated as follows: $E_{00}=\sqrt{\left(\frac{L}{K_{L} S_{L}}\right)^{2}+\left(\frac{C}{K_{C} S_{C}}\right)^{2}+\left(\frac{H}{K_{H} S_{H}}\right)^{2}+R_{T}\left(\frac{C}{K_{C} S_{C}}\right)\left(\frac{H}{K_{H} S_{H}}\right)}$ , where $L, C$ and $H$ is the differences in lightness, chroma, and hue for a pair of samples in CIEDE2000, and $R_{T}$ is a function (the so-called rotation function) that accounts for the interaction between chroma and hue differences in the blue 
region. The weighting functions, $\mathrm{S}_{\mathrm{L}}, \mathrm{S}_{\mathrm{C}}$ and $\mathrm{S}_{\mathrm{H}}$ are used to adjust the total color difference for the variation in the location of the color difference pair in the L, a, b coordinates and the parametric factors, $\mathrm{K}_{\mathrm{L}}, \mathrm{K}_{\mathrm{C}}$ and $\mathrm{K}_{\mathrm{H}}$ are the corrected terms for experimental conditions. The parametric factors of the CIEDE2000 color difference formula were set to 1 .

\section{Cytotoxicity Experiment}

The groups with the highest flexural strength were selected in light- and dual-cured resin; unpolymerized resin composites were made into resin specimens with a diameter of $0.6 \mathrm{~cm}$ and a thickness of $0.15 \mathrm{~cm}$. Each group had 10 resin specimens, resulting in a total surface area of $8.478 \mathrm{~cm}^{2}$. The extracting liquid was prepared according to the ISO1099312 international standard. After sterilizing with a UV lamp for $30 \mathrm{~min}, 10$ test pieces were placed in a centrifuge tube, and $2.5 \mathrm{~mL}$ of DMEM (Gibco, USA) complete medium was added according to the standard of the surface area of specimens/volume of medium $=1.25 \mathrm{~cm}^{2} / \mathrm{mL}$. All specimens were water stored at $37^{\circ} \mathrm{C}$ for $24 \mathrm{~h}$; we then collected the extract.

The L929 mouse fibroblast cells (Cell Bank of the Chinese Academy of Sciences, Shanghai, China) were seeded in 96-well plates at a density of 5000 cells/well, and the experimental groups were cultured with their respective elutes. A control group was replaced with DMEM medium containing $10 \%$ fetal bovine serum (Gibco, USA). Subsequently, the CCK-8 reagent (Dojindo Molecular Technology, Kumamoto, Japan) was used to detect cytotoxicity. After incubation for 24, 72, and $120 \mathrm{~h}$, a microplate reader (SpectraMax M5; Molecular Devices LLC, Sunnyvale, CA, USA) was used to measure the optical density (OD) at $450 \mathrm{~nm}$. Wells with the CCK-8 solution but without cells were used as the blank control. Optical density values (OD) were represented as the mean of absorbance for 5 wells from each group. Cell cytotoxicity was evaluated according to the relative growth rate (RGR) of the cells, and RGRs were calculated using the following equation:

The RGR= OD of the experimental group - OD of the blank group/OD of the control group - OD of the blank group $\times 100 \%$.

As mentioned above, another 24-well plate was used for the cultivation of L929, with a cell density of $5 \times 10^{5}$ / $\mathrm{mL}$. Different eluents were used to replace the culture medium containing $10 \%$ fetal bovine serum, after incubation for 24, 72, and $120 \mathrm{~h}$. The morphological changes of the fibroblasts were directly observed and photographed by a phase-contrast microscope (Nikon, Japan).

\section{Statistical Analysis}

We separately analyzed three-point bending strength, and TP values of the resin composites using SPSS 22 (IBM SPSS Inc., Chicago, IL, USA). After verifying normal distribution and homogeneity of the variance via Levene's test, we used a multivariate ANOVA and leastsignificant-difference to compare differences between groups. We considered $\mathrm{P}<0.05$ statistically significant.

\section{Results FTIR}

Figure 1A and B show the FTIR spectra of unconditioned and MDP-conditioned nano- or micro-zirconia fillers within the range of $3500-500 \mathrm{~cm}^{-1}$ and the peak-fitted spectra of MDP-conditioned nano- and micro-zirconia fillers within the range of $1200-950 \mathrm{~cm}^{-1}$. The absorption bands at $2930 \mathrm{~cm}^{-1}$ and $2850 \mathrm{~cm}^{-1}$ correspond to the $\mathrm{CH}_{2}-$ stretching vibration. $^{30}$ The peaks of MDP-conditioned nano- and micro-zirconia fillers located at $1719 \mathrm{~cm}^{-1}$ due to $\mathrm{C}=\mathrm{O}$ stretching vibration and absorption peaks near $1637 \mathrm{~cm}^{-1}$ were attributed to the $\mathrm{C}=\mathrm{C}$ bond. ${ }^{31}$ The peaks corresponding to the $\mathrm{P}-\mathrm{O}$ bond of MDP-conditioned nano-zirconia fillers were located at 985.5 and $1082 \mathrm{~cm}^{-1}$ while those for MDP-conditioned micro-zirconia fillers were located at 972.6 and $1083.7 \mathrm{~cm}^{-1.25}$

\section{XPS}

XPS spectra of unconditioned and MDP-conditioned nanozirconia and micro-zirconia are shown in Figure 2. We detected $\mathrm{P}$ spectrum in the wide-scan spectra of MDPconditioned nano- and micro -zirconia (Figure 2A and B). According to the XPS O1s spectra of the MDP-conditioned nano-zirconia fillers (Figure 2E), we divided peak decomposition of XPS O1s spectra into four contributions. The peak located at $529.5 \mathrm{eV}$ was attributed to the $\mathrm{Zr}-\mathrm{O}-$ $\mathrm{Zr}$ bond, that at $530.5 \mathrm{eV}$ was the $\mathrm{Zr}-\mathrm{O}-\mathrm{P}$ bond, that at $531.9 \mathrm{eV}$ was the $\mathrm{OH}-$ bond and that at $533.1 \mathrm{eV}$ was the $\mathrm{C}-\mathrm{O}$ bond. $^{32}$ The peak area of $\mathrm{Zr}-\mathrm{O}-\mathrm{P}$ bond was $39.91 \%$. In the MDP-conditioned micro-zirconia fillers (Figure $2 \mathrm{~F}$ ), we likewise found four component peaks. The peaks located at $529.5 \mathrm{eV}, 530.6 \mathrm{eV}, 531.9 \mathrm{eV}$, and $533.0 \mathrm{eV}$ were attributed to the $\mathrm{Zr}-\mathrm{O}-\mathrm{Zr}, \mathrm{Zr}-\mathrm{O}-\mathrm{P}, \mathrm{OH}-, \mathrm{C}-\mathrm{O}$, respectively. $^{32}$ The peak area of $\mathrm{Zr}-\mathrm{O}-\mathrm{P}$ bond was $34.52 \%$. 

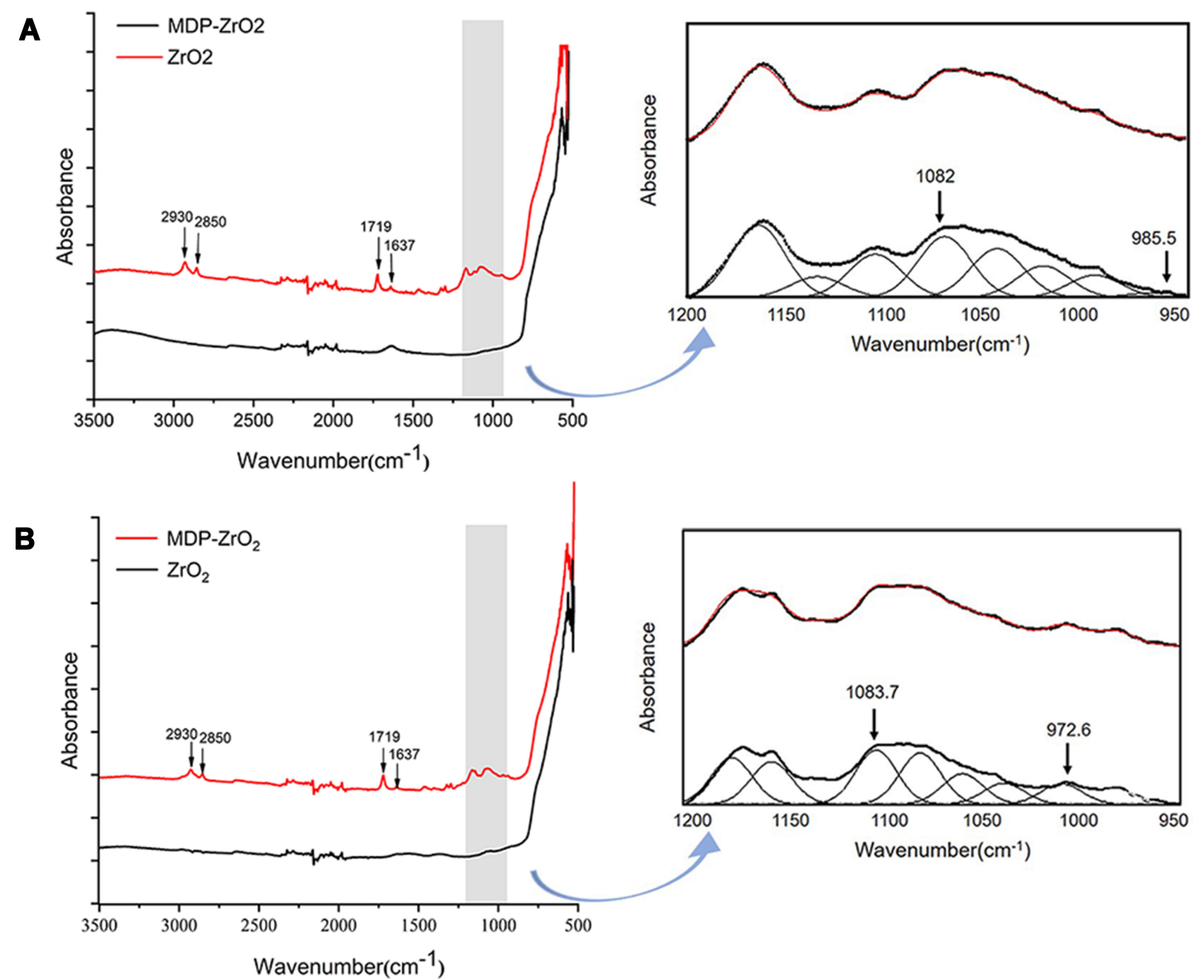

Figure I (A) FTIR spectra of the MDP-conditioned and unconditioned nano-zirconia fillers in the range of $3500-500 \mathrm{~cm}^{-1}$ and peak-fitted FTIR spectra of MDP-conditioned nano-zirconia fillers in the range of $1200-950 \mathrm{~cm}^{-1}$. The peaks corresponding to the P-O bond were located at 985.5 and I082 $\mathrm{cm}{ }^{-1}$; (B) FTIR spectra of the MDPconditioned and unconditioned micro-zirconia fillers in the range of $3500-500 \mathrm{~cm}^{-1}$ and peak-fitted FTIR spectra of MDP-conditioned micro-zirconia fillers in the range of 1200-950 $\mathrm{cm}^{-1}$. The peaks corresponding to the P-O bond were located at 972.6 and $1083.7 \mathrm{~cm}^{-1}$. The absorption band of MDP-conditioned nano- and micro-zirconia fillers at 2930 and $2850 \mathrm{~cm}^{-1}$ correspond to the $-\mathrm{CH}_{2}-$ stretching vibration. The peaks located at 1719 and $1637 \mathrm{~cm}^{-1}$ were attributed to $\mathrm{C}=\mathrm{O}$ bond and $\mathrm{C}=\mathrm{C}$ bond, respectively.

Morphology Observation of Zirconia and Silica Fillers

The SEM images of micro-silica or micro-zirconia particles, and the TEM images of nano-silica or nanozirconia particles are shown in Figure 3. Micro-silica (Figure 3A) and micro-zirconia (Figure 3B) were irregular particles with a size range of $5-10 \mu \mathrm{m}$, and nanosilica (Figure 3C) and nano-zirconia (Figure 3E) fillers were circular particles with a particle size of 20-50 $\mathrm{nm}$. Figure $3 \mathrm{D}$ and $\mathrm{F}$ show the electron diffraction pattern of nano-silica and nano-zirconia particles. There were no scattering points in the electron diffraction pattern of nano-silica, indicating that it is an amorphous structure. Conversely, the diffraction points or discontinuous diffraction rings in the electron diffraction pattern of nano zirconia revealed that it was a crystal structure.

\section{Scanning Electron Microscope (SEM) and Energy-Dispersive Spectrometry (EDS) Mapping}

The SEM images and EDS maps of light-cured (L-55si+5zr, L-55si+5Mzr, L-30si+30zr, L-30si+30Mzr) and dual-cured (D-55si+5zr, D-55si+5Mzr, D-30si+30zr, D-30si+30Mzr, D-5si+55zr, D-5si+55Mzr) resin composites are shown in Figure 4. In the light-cured resin composites (Figure 4A), 
A $\quad$ - unconditioned
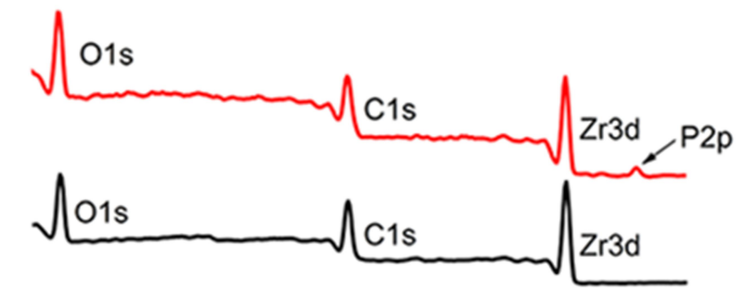

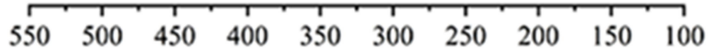

Binding Energy $(\mathrm{eV})$

C
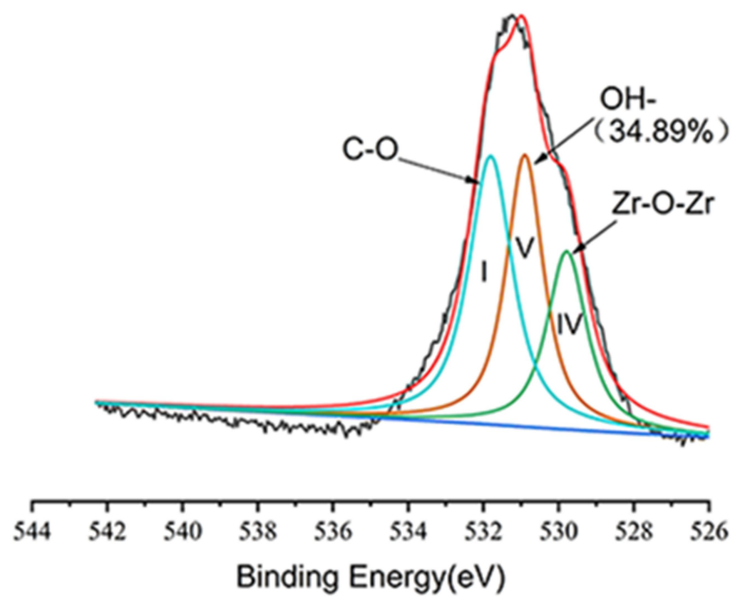

E
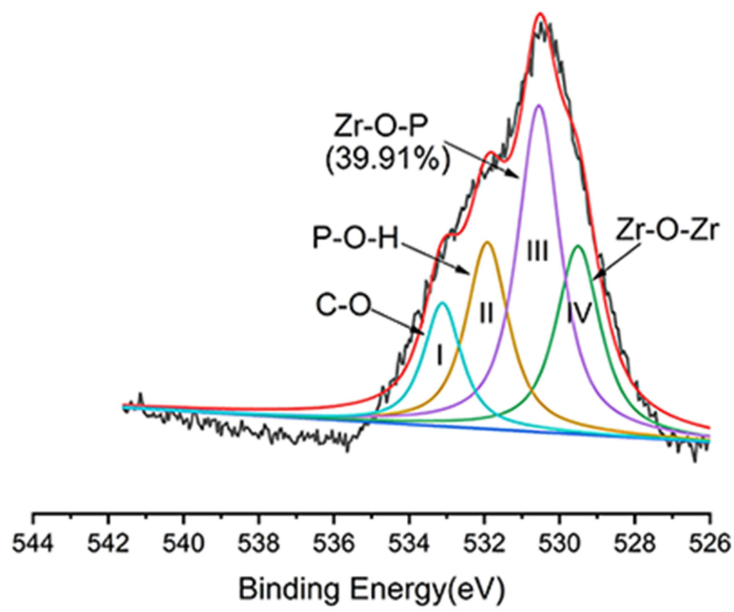

B
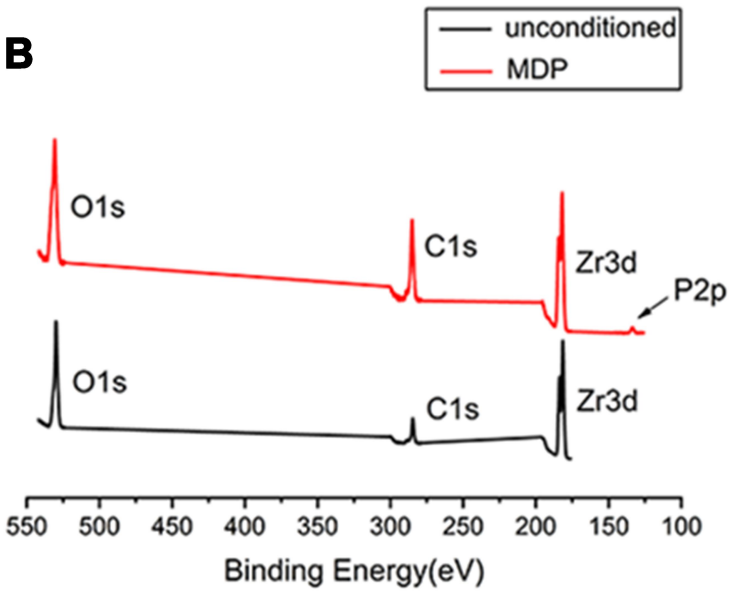

D
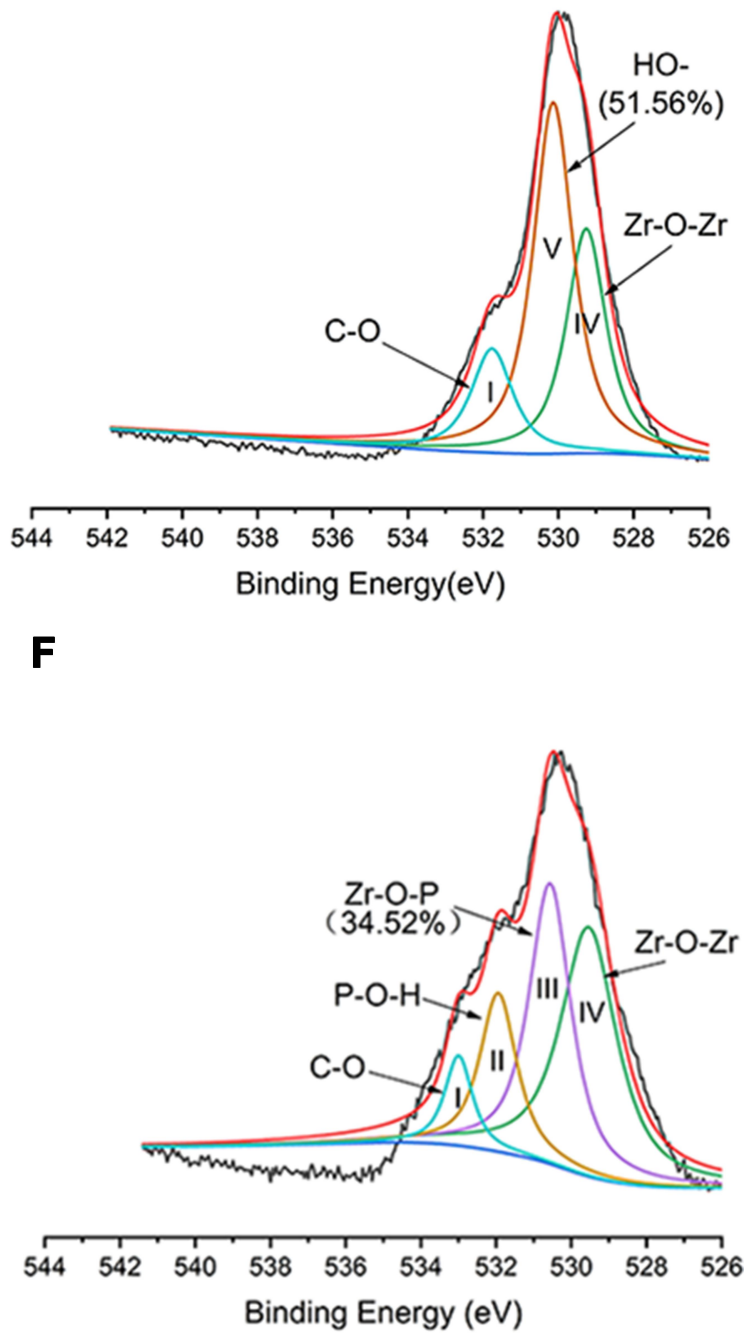

Figure 2 (A) Wide-scan X-ray photoelectron spectroscopy spectra of the unconditioned and MDP-conditioned nano-zirconia fillers; (B) wide-scan X-ray photoelectron spectroscopy spectra of the unconditioned and MDP-conditioned micro-zirconia fillers; (C) narrow-scan Ols spectra of the unconditioned nano-zirconia fillers; (D) narrowscan OIs spectra of the unconditioned micro-zirconia fillers; (E) narrow-scan OIs spectra of the MDP-conditioned nano-zirconia fillers; and (F) narrow-scan OIs spectra of the MDP-conditioned micro-zirconia fillers. I (C-O), II (P-O-H), III ( $\mathrm{Zr}-\mathrm{O}-\mathrm{P})$, IV ( $\mathrm{Zr}-\mathrm{O}-\mathrm{Zr}), \mathrm{V}(\mathrm{OH}-)$ represent the different deconvoluted peaks within the main peak. 


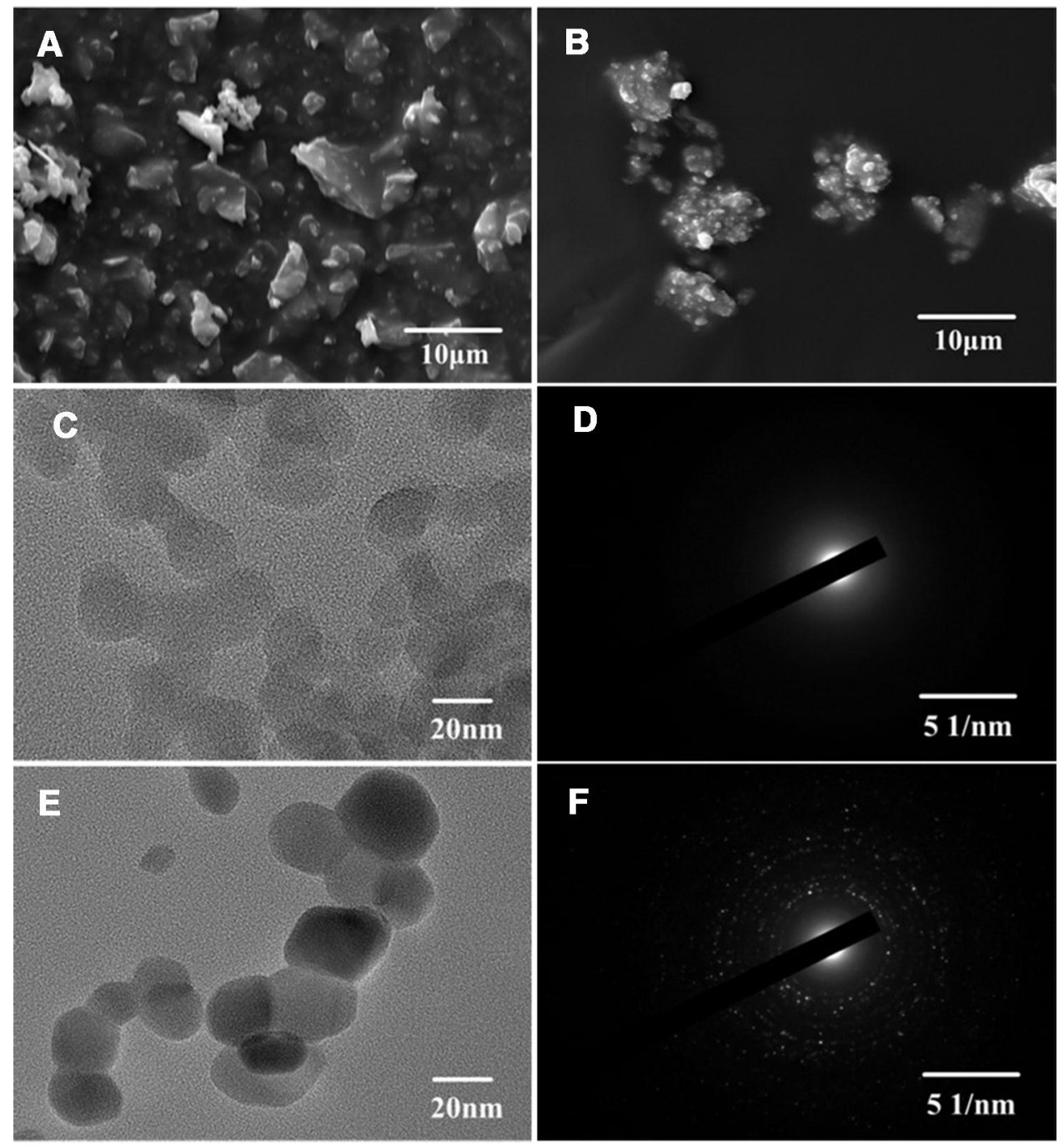

Figure 3 (A) SEM image of the unconditioned micro-silica fillers; (B) SEM image of the unconditioned micro-zirconia fillers; (C) transmission electron micrograph of the unconditioned nano-silica fillers; (D) electron diffraction pattern of the unconditioned nano-silica fillers; (E) transmission electron micrograph of the unconditioned nanozirconia fillers; and $(\mathbf{F})$ electron diffraction pattern of the unconditioned nano-zirconia fillers.

nano-zirconia and micro-silica fillers dispersed well when the amount of nano-zirconia fillers is $5 \mathrm{wt} \%$. while the proportion of nano-zirconia fillers in resin up to $30 \%$, zirconia fillers agglomerated apparently. Obvious clusters can be observed when resin materials contain 5\% MDP-zirconia in dual-cured resin composites (Figure 4B) and the degree of aggregation raises as the content of zirconia increases. However, in the D-5si + 55zr group, parts of the microzirconia fillers agglomerates split away from the resin surface; in contrast, this was not observed in the D-5si $+55 \mathrm{Mzr}$ group. The SEM images and EDS maps of resin composites of L-60si, L-50si+10zr, L-50si+10Mzr, L-40si+20zr, L-40si +20Mzr，D-60si，D-50si+10zr，D-50si+10Mzr，D-40si $+20 \mathrm{zr}, \mathrm{D}-40 \mathrm{si}+20 \mathrm{Mzr}$ are shown in Supplemental Figures A and $\underline{B}$.

\section{Three-Point Bending Strength, Elastic Modulus, and Weibull Analysis}

Figure 5A and $\mathrm{B}$ shows the three-point bending strengths of the light- and dual-cured groups. We did not test the performance of the 14 ruled out groups mentioned above. All threepoint bending-strength values conformed to the homogeneity of variance and normal distribution $(\mathrm{P}>0.05)$.

Statistical differences were observed between different mass fractions of MDP-conditioned and unconditioned micro- or nano-zirconia fillers. Versus silica-filled resin composites, the addition of nano-zirconia fillers improved the flexural strength of the resin composites. The resin composites with $5 \mathrm{wt} \%$ MDP-conditioned nano-zirconia fillers presented the highest flexural strength and exceeded $140 \mathrm{MPa}$, while the flexural strength gradually decreases 

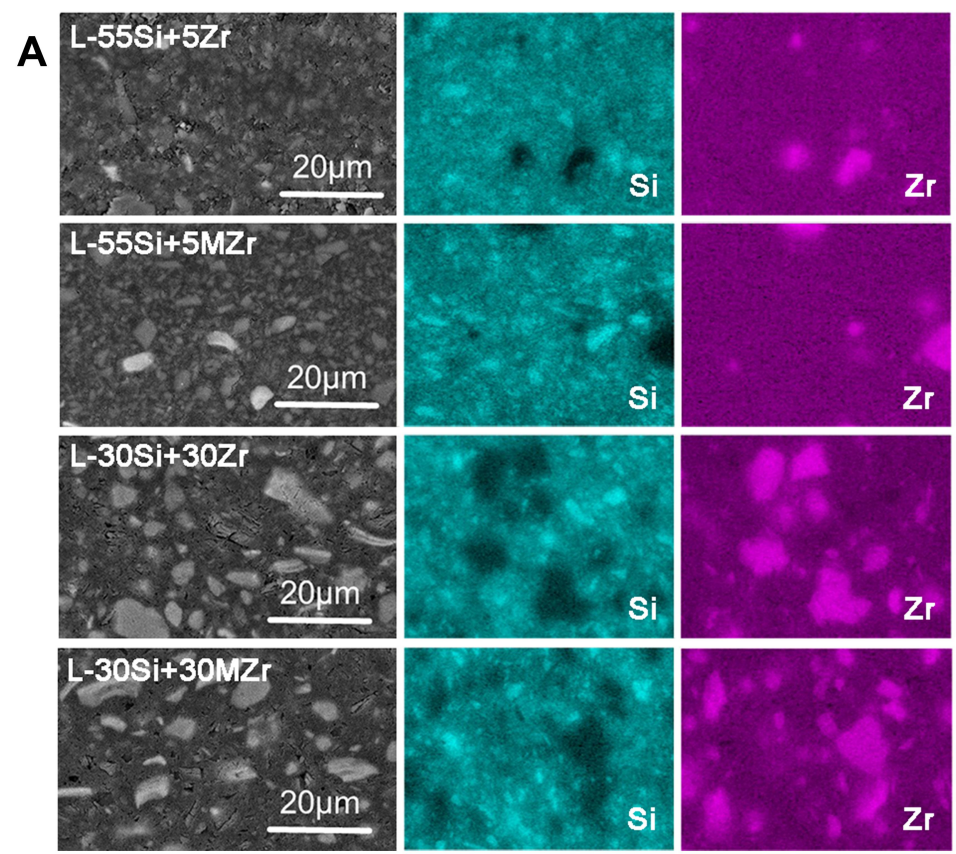

B
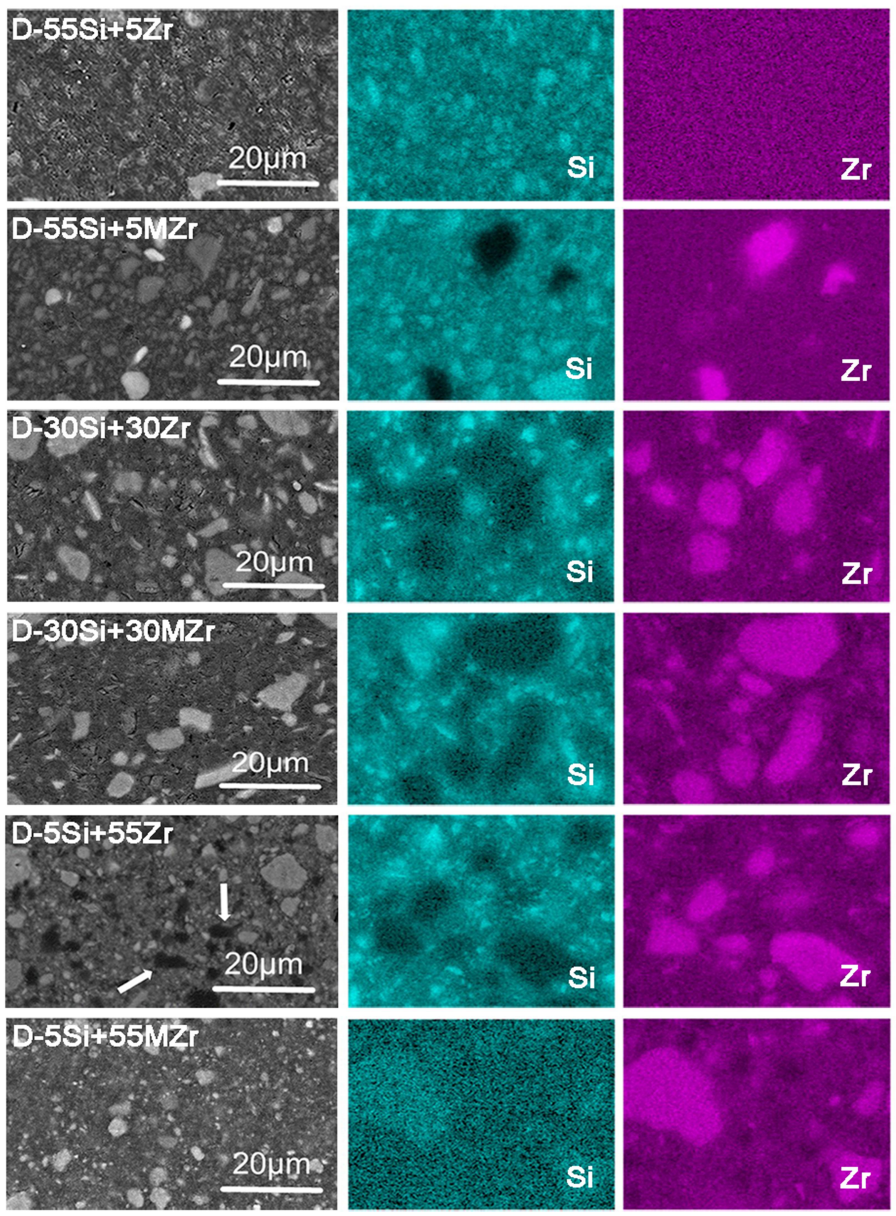

Figure 4 (A) SEM images and EDS maps of light-cured resin composites of L-55si+5zr, L-55si+5Mzr, L-30si+30zr, L-30si+30Mzr; (B) SEM images and EDS maps of dualcured resin composites of D-55si+5zr, D-55si+5Mzr, D-30si+30zr, D-30si+30Mzr, D-5si+55zr, D-5si+55Mzr. The arrows represent the pits left by the fillers splitting away from the resin surface. 
A

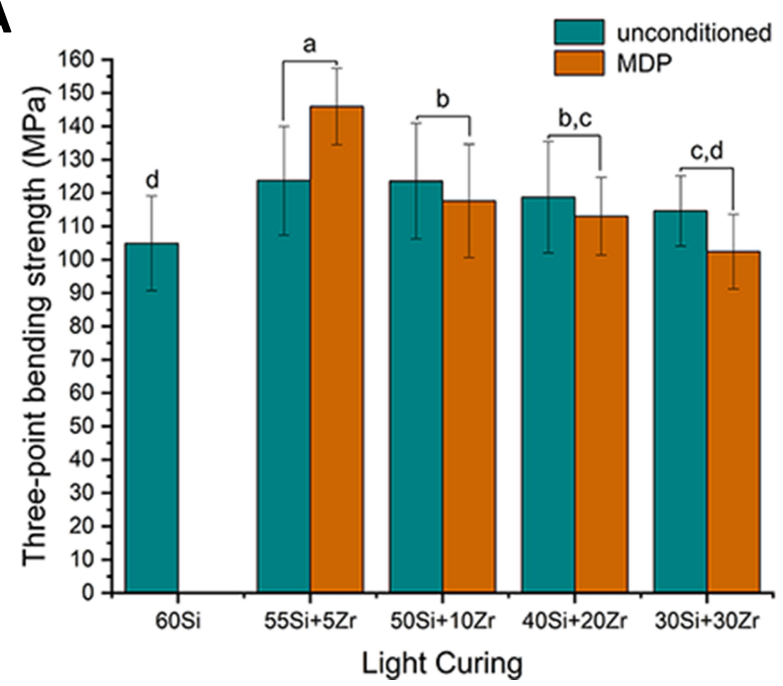

B

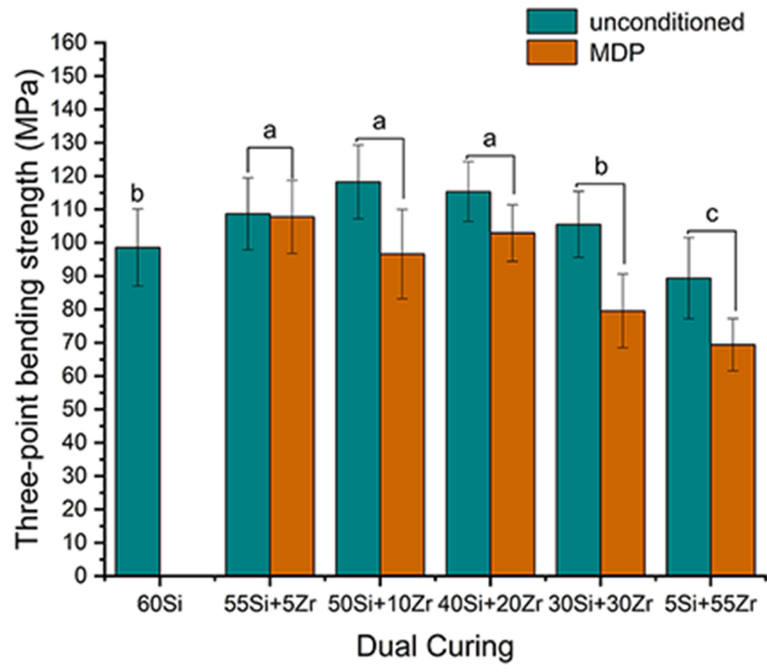

Figure 5 (A) Mean values of three-point bending strength of the light-cured resin composites; (B) mean values of three-point bending strength of the dual-cured resin composites. Same superscript letters $(a-d)$ indicates no significant difference between the groups $(P>0.05)$.

with the further increase of zirconia content. When the mass fractions of micro- or nano-zirconia fillers are $>10 \mathrm{wt}$ $\%$, the resin composites with unconditioned zirconia particles showed better flexural strength than those with MDP-conditioned zirconia particles.

Differences were statistically significant from dualcured experimental groups (Figure 5B). When silica was utilized as the main filler, the addition of $5 \mathrm{wt} \%-20 \mathrm{wt} \%$ unconditioned nano-zirconia filler improved the flexural strength of the resin. Conversely, the flexural strength was significantly declined when micro-zirconia was used. In addition, as opposed to light-cured groups, the MDP

Table 2 Mean SD Values of Elastic Modulus of the Light- and Dual-Cured Resin Composites

\begin{tabular}{|c|c|c|}
\hline & \multicolumn{2}{|c|}{ Elastic Modulus (GPa) } \\
\hline & Light Curing & Dual Curing \\
\hline $60 \mathrm{si}$ & $9.93 \pm 0.83^{\mathrm{a}}$ & $7.22 \pm 0.76^{b}$ \\
\hline $55 \mathrm{si}+5 \mathrm{zr}$ & $9.28 \pm 0.56^{\mathrm{a}}$ & $8.81 \pm 0.58^{\text {ef }}$ \\
\hline $55 s i+5 M z r$ & $9.7 I \pm 0.84^{\mathrm{a}}$ & $9.25 \pm 0.98^{f}$ \\
\hline $50 \mathrm{si}+10 \mathrm{zr}$ & $9.46 \pm 0.69^{\mathrm{a}}$ & $8.48 \pm 0.62^{e}$ \\
\hline $50 \mathrm{si}+10 \mathrm{Mzr}$ & $9.36 \pm 0.72^{\mathrm{a}}$ & $8.35 \pm 0.70^{\text {de }}$ \\
\hline $40 \mathrm{si}+20 \mathrm{zr}$ & $8.49 \pm 0.39^{b}$ & $7.78 \pm 0.45^{b c}$ \\
\hline $40 \mathrm{si}+20 \mathrm{Mzr}$ & $8.53 \pm 0.54^{b}$ & $7.88 \pm 0.47^{\mathrm{cd}}$ \\
\hline $30 \mathrm{si}+30 \mathrm{zr}$ & $8.31 \pm 0.70^{b}$ & $7.59 \pm 0.84^{\mathrm{bc}}$ \\
\hline $30 \mathrm{si}+30 \mathrm{Mzr}$ & $8.40 \pm 0.46^{\mathrm{b}}$ & $7.44 \pm 0.45^{b c}$ \\
\hline $5 s i+55 z r$ & & $6.5 I \pm 0.5 I^{\mathrm{a}}$ \\
\hline $5 s i+55 \mathrm{Mzr}$ & & $6.62 \pm 0.67^{\mathrm{a}}$ \\
\hline
\end{tabular}

Note: Same superscript letters ${ }^{\text {a-f }}$ indicate no significant difference between the groups $(P>0.05)$. conditioning in dual-cured groups was unable to further enhance the flexural strength.

Table 2 shows the mean values of elastic modulus of the light-cured and dual-cured groups. In brief, resin composites presented a lower elastic modulus when the ratio of nano-zirconia increased, and MDP conditioning had no obvious effect on the elastic modulus of the resin.

Figure 6A and $\mathrm{B}$ show the Weibull distribution of the $95 \%$ confidence interval of light-cured and dualcured groups. A high Weibull modulus indicated a smaller error range and greater structural reliability of the material. The Weibull modulus of three-point bending strength for each group is $>8$, indicating a reliable date. ${ }^{33}$

\section{Translucency Parameter}

Figure 7A and B show the translucence of the light- and the dual-cured groups wherein the translucence of the silica group was the highest (over 5). However, the translucence of the resin with $5 \mathrm{wt} \%$ nano-zirconia fillers decreased significantly, and the translucence of the resin with $55 \mathrm{wt} \%$ micro-zirconia fillers was lowest (falling below 0.5 ).

\section{Cytotoxicity Experiment}

We selected experiment groups with highest flexural strength (L-55si+5Mzr, L-55si+5Mzr, D-50si+10zr and $\mathrm{D}-50 \mathrm{si}+10 \mathrm{Mzr}$ ) individually in light-cured initiator system and dual-cured initiator system to evaluate cytotoxicity. The relative cell proliferations are shown in Figure 8. 

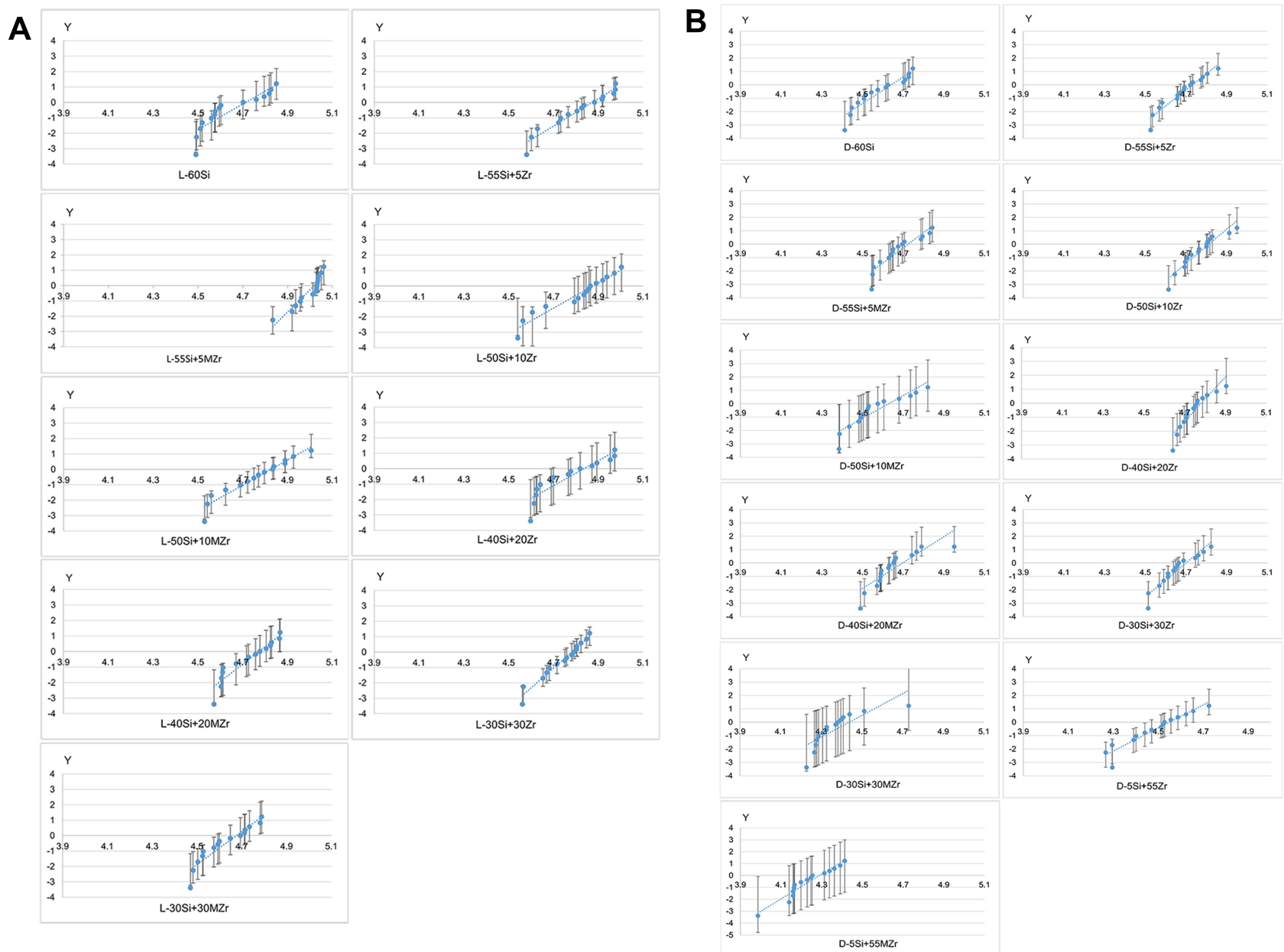

Figure 6 (A) Weibull distribution plot with 95\% confidence intervals of light-cured resin composites; (B) Weibull distribution plot with $95 \%$ confidence intervals of dualcured resin composites.

The cell proliferation of the control group was better than that of the experimental groups, and there is no significant difference between the experimental groups.

The RGR and cytotoxicity grade of each group are shown in Table 3. The RGR values of the experimental groups were $>80 \%$. The cytotoxicity grade was Grade 1 , and the resin material had no significant cell cytotoxicity. ${ }^{18}$

Figure 9 shows the growth status of cells in each group after 1,3 , and 5 days. The cell morphology was basically normal, and the growth trend was similar. After 5 days of culture, cells in each group basically covered the bottom of the well, suggesting that the biocompatibility was good.

\section{Discussion}

Our previous study proved that adding a small amount of zirconia with or without surface treatment was attributed to the mechanical properties of the resin composites. ${ }^{18}$ The feasibility of large scale addition of nano-zirconia fillers has not yet been studied before. Thus, we investigated the mechanical properties of nanohybrid composites with different mass fractions of unconditioned or MDP-conditioned zirconia filler in micro- or nano-sizes, under various initiator systems. Here, nanohybrid fillers were mixed with silica and zirconia, and the weight ratio was controlled at $60 \mathrm{wt} \%$. In the process of making resin specimens, we found that in the total of 14 group specimens cannot be obtained successfully and the main reasons are as follows: 1) more than 10 $w t \%$ nano-silica fillers could not entirely melt into the matrix (L-20si+40zr, L-20si+40Mzr, L-10si+50zr, L-10si +50Mzr, D-20si+40zr, D-20si+40Mzr, D-10si+50zr, $\mathrm{D}-10 \mathrm{si}+50 \mathrm{Mzr})$; 2) the translucence was too low for resin materials to be cured completely (L-5si+55zr and L-5si $+55 \mathrm{Mzr}$ ); 3) the resin materials were too thin to be shaped and molded (L-60zr, L-60Mzr, D-60zr and D-60Mzr). Therefore, we did not test the flexural strength, translucence and cytotoxicity of these groups. 
A

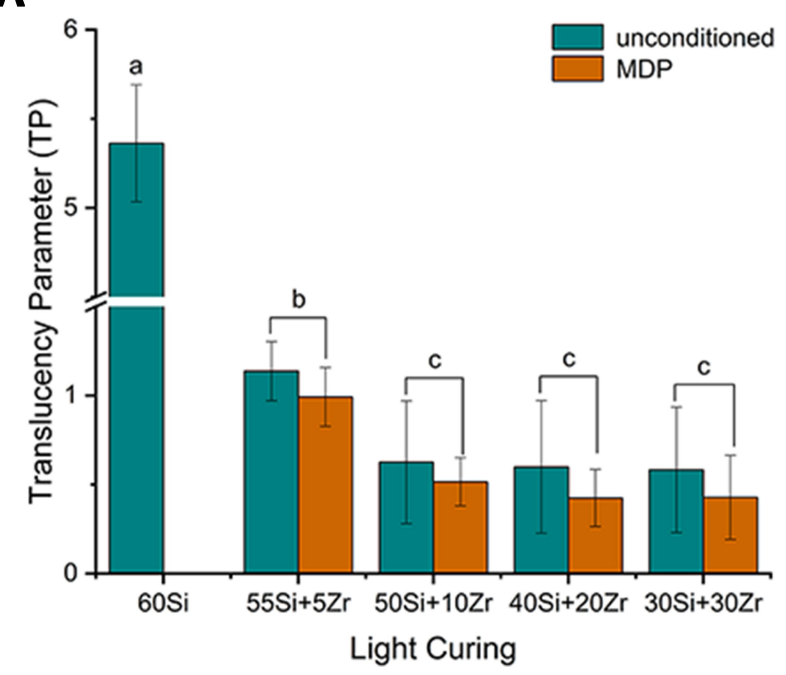

B

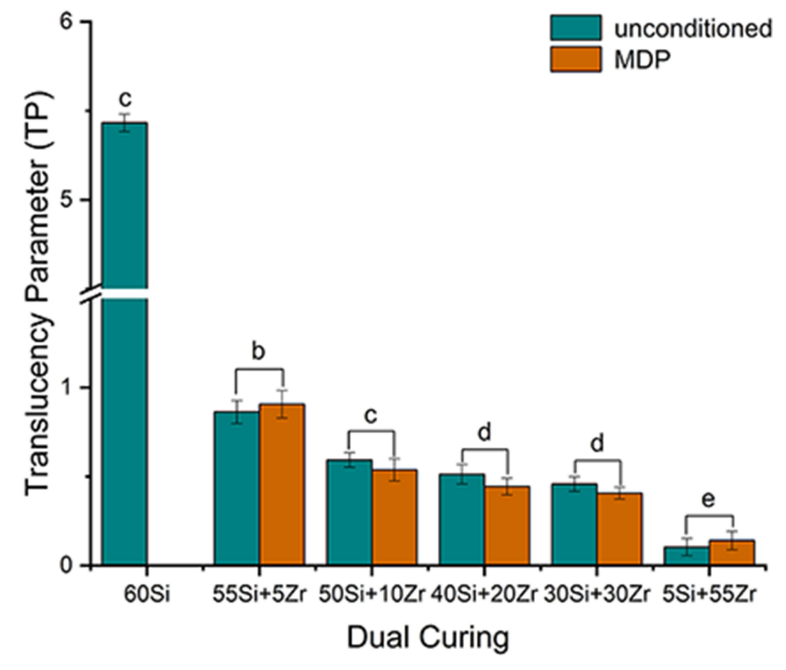

Figure 7 (A) Mean values of translucency parameter of the light-cured resin composites; (B) mean values of translucency parameter of the dual-cured resin composites. Same superscript letters $(a-e)$ indicates no significant difference between the groups $(P>0.05)$.

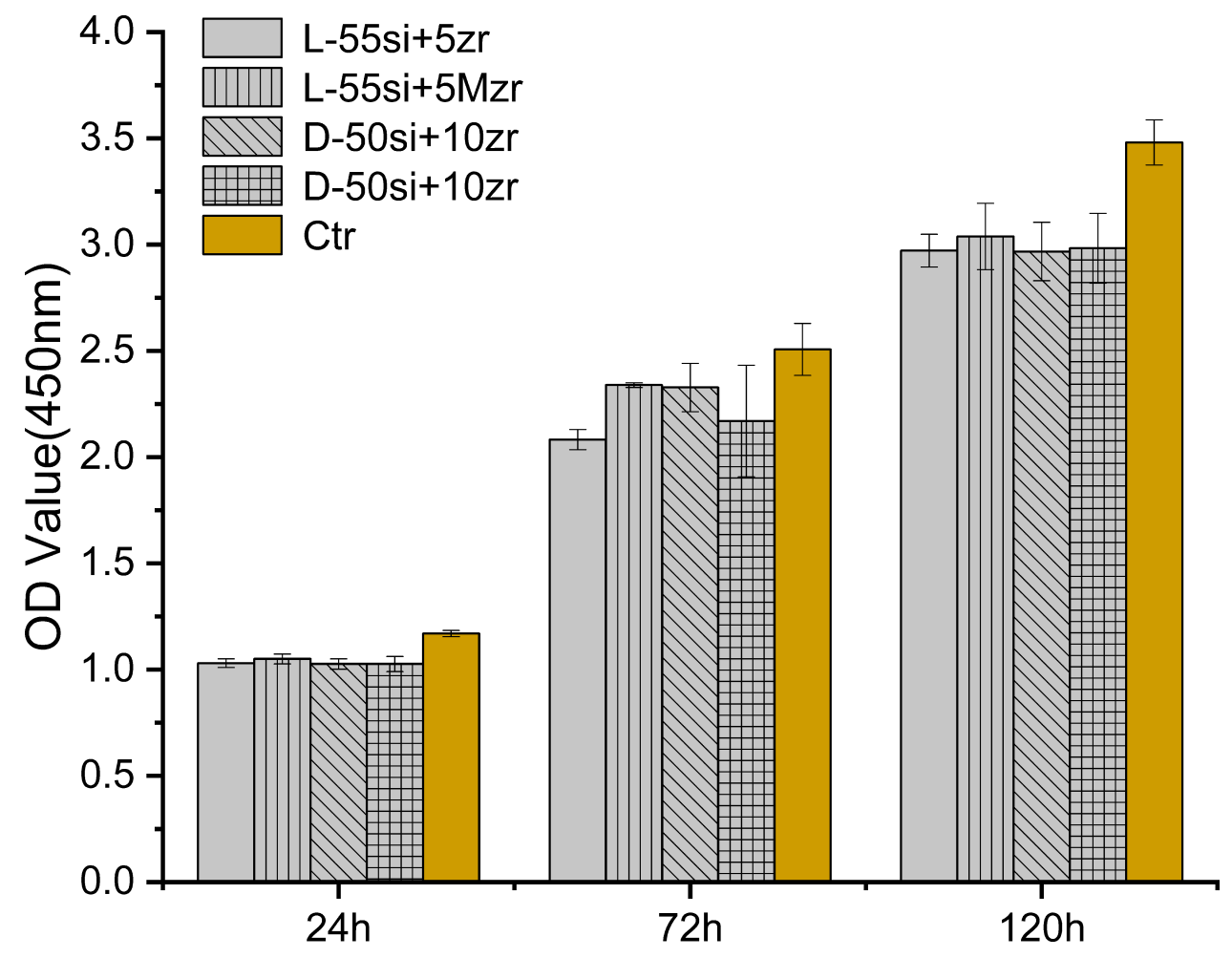

Figure 8 Relative cell proliferations of the experimental groups and the control group.

According to the ISO4049 standard, the flexural strength of resin-composite materials should be $>80$ $\mathrm{MPa},{ }^{34}$ and all experimental resin composites with lightcured initiator system in the present study met this standard. The three-point bending test shows that the addition of nano-zirconia fillers with a light-cured initiator system of nanohybrid composites improved the flexural strength of resin composites compared to silica-filled resin composites. The flexural strength of the resin decreased as the proportion exceeded $10 \mathrm{wt} \%$. The resin composites with 5 $\mathrm{wt} \%$ MDP-conditioned nano-zirconia presented the highest Weibull modulus and flexural strength (>140 MPa). 
Table 3 Relative Growth Rate (RGR) and Cytotoxicity Grade (CG) of Resin Composites

\begin{tabular}{|c|c|c|c|c|c|c|}
\hline & \multicolumn{2}{|l|}{$24 \mathrm{~h}$} & \multicolumn{2}{|l|}{$72 \mathrm{~h}$} & \multicolumn{2}{|l|}{ I20h } \\
\hline & RGR & CG & RGR & CG & RGR & CG \\
\hline$L-55 s i+5 z r$ & $86.07 \%$ & I & $82.00 \%$ & 1 & $84.61 \%$ & 1 \\
\hline L-55si+5Mzr & $88.07 \%$ & I & $92.89 \%$ & I & $86.62 \%$ & 1 \\
\hline D-50si+10zr & $85.67 \%$ & 1 & $92.40 \%$ & 1 & $84.48 \%$ & 1 \\
\hline D-50si+10Mzr & $85.67 \%$ & 1 & $85.70 \%$ & I & $84.94 \%$ & 1 \\
\hline
\end{tabular}

This was consistent with the previous experimental research, ${ }^{17}$ both indicating that it has a clinical application value to add some amount of surface-conditioned zirconia fillers to resin composites. However, when the ratio of nano-zirconia particles exceeded $10 \mathrm{wt} \%$, the flexural strength of MDP-conditioned groups decreased more significantly than the unconditioned groups. This may be explained by the self-condensation of MDP or interaction between $\gamma$-MPS and 10-MDP, ${ }^{35}$ which means that part of the MDP may contribute to combine with the resin matrix, while a larger part of the MDP may self-condense, further promoting the agglomeration of fillers, which led to the uneven material distribution.

Previous studies revealed that the inertness of zirconia makes it difficult to form chemical bonds with the resin matrix. ${ }^{36}$ Furthermore, there is an obvious tendency for nano-zirconia fillers to agglomerate, resulting in fillers that are unevenly dispersed. Here, the acid functional monomer MDP served to condition zirconia fillers to promote the dispersion of nano-zirconia particles in resin and improve its binding with the matrix. At one end of the MDP, the phosphoric acid group can combine with zirconia to form a $\mathrm{Zr}-\mathrm{O}-\mathrm{P}$ bond. At the other end, the carbon-carbon double bond can react with the resin matrix. ${ }^{37,38}$ Theoretically, MDP conditioning is conducive to the bonds with fillers in the matrix. The infrared spectra of nano- and micro-zirconia with surface treatment showed absorbance intensities of the MDP $\mathrm{C}=\mathrm{C}$ peak at $1637 \mathrm{~cm}^{-1}$ as well as MDP $\mathrm{C}=\mathrm{O}$ peak at $1719 \mathrm{~cm}^{-1}$, suggesting that chemical reaction occurred between MDP and zirconia. This is consistent with the previous experimental results. The $\mathrm{Zr}-\mathrm{O}-\mathrm{P}$ peak occurred at $100-150 \mathrm{eV}$ in the XPS spectra of MDP-modified microzirconia filler and nano-zirconia filler. In addition, the corresponding O1s spectra showed that the peak area of $\mathrm{Zr}-\mathrm{O}-\mathrm{P}$ bond was $30-40 \%$, indicating the effectiveness of MDPconditioned zirconia. However, it was unexpected that MDP conditioning depended on the filler content for the effective dispersion of the fillers in the resin matrix.
According to the SEM images and EDS maps, the fillers would obviously agglomerate when the ratio of the MDPconditioned nano-zirconia particles exceeded $10 \mathrm{wt} \%$ regardless of the initiator system resin composites. Among the resins with the same ratio of fillers, the distribution of fillers in the MDP-conditioned group was not improved versus the unconditioned group. Even in the D-5si+55Mzr group, fillers were exfoliated from the resin matrix. The disordered distribution of fillers significantly and distinctly affected the mechanical properties of the nanohybrid composites.

During the process of manufacturing composites, we found that the zirconia fillers were prone to agglomerate when the MDP-conditioned zirconia was added to the resin matrix. As a result, agglomerates must be ground well to ensure the fillers are evenly distributed. This may be explained by the self-condensation of the 10-MDP molecule or the interaction between $\gamma$-MPS and 10-MDP, which further promotes the agglomeration of zirconia particles. The amount of MDP-conditioned zirconia fillers added to the resin needs to be controlled. When the MDP-conditioned zirconia exceeded a certain percentage, it had adverse effects on the uniform dispersion of the fillers in the resin composites, as well as the mechanical properties of the product.

The current test results show that the light-cured resin composites presented a significant decrease in translucence when adding only $5 \mathrm{wt} \%$ zirconia fillers. We speculate that the efficiency of light-cured initiator system alone would be reduced or even eliminated. In this study, the translucence of the silica group was $>5$. However, the translucence decreased to 1 when $5 \mathrm{wt} \%$ nano-zirconia fillers were added to the resin. The transparency decreased below 0.5 when the micro-zirconia fillers increased to 55 $w t \%$. Therefore, it was necessary to introduce a self-cured system into the resin containing a large ratio of zirconia fillers. However, the flexural strength and elastic modulus of dual-cured resin still failed to be satisfied because the flexural strength of the nanohybrid resin composites failed to exceed $120 \mathrm{MPa}$ in the dual-cured groups. 

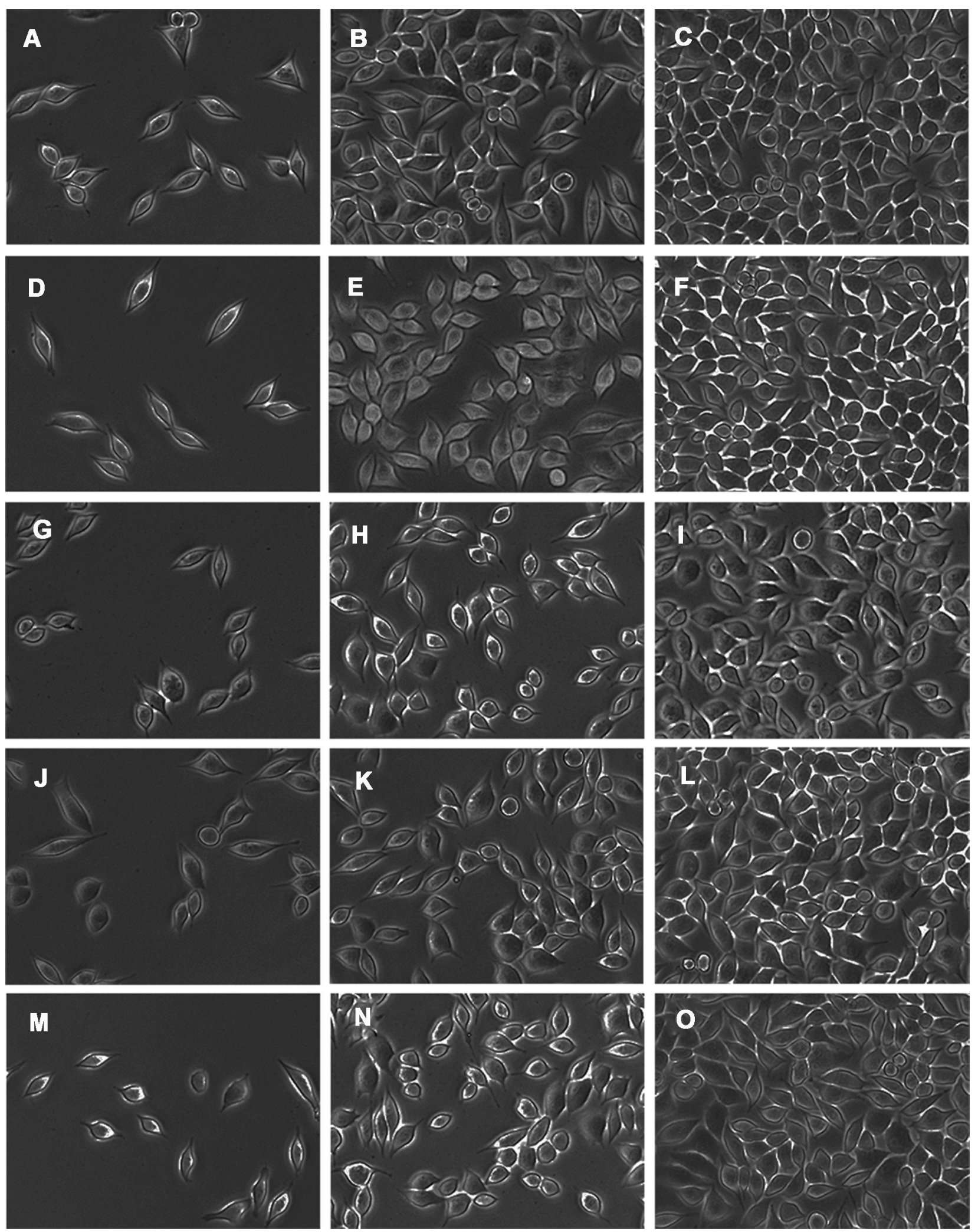

Figure 9 Cell morphology in each group after I (A, D, G, J, M), 3 (B, E, H, K, N) and 5 (C, F, I, L, O) days of cell culture. (A-C): L-55si+5Zr group; (D-F): L-55si+5Mzr group; (G-I): D-50si+10zr; (J-L): D-50si+10Mzr; and (M-O): control group. 
As the zirconia content increased, the flexural strength of dual-cured resin composites first increased and then decreased; samples containing $10 \mathrm{wt} \%$ nano-zirconia fillers were the best. The resin composites with untreated nano-zirconia had better flexural strength than the MDP-conditioned groups, and the flexural strength in the groups with $30 \mathrm{wt} \%$ and $55 \mathrm{wt} \% \mathrm{MDP}$ zirconia was lower than $80 \mathrm{MPa}$. Nevertheless, we acknowledge that in terms of the mechanical properties of the resin, the dual-cured initiator system failed to show the expected advantages over the light-cured groups.

Fortunately, the low translucence also has positive effects: it improves the masking ability. The results found that adding some amount of zirconia fillers in resin composites increases the mechanical properties and masking ability, conforming to the ISO4049 standard, wherein the flexural strength of resin luting cements should be $>50$ $\mathrm{MPa}$. We also found that the addition of a large proportion of nano- or micro-zirconia fillers sharply increased the fluidity of material in the related pre-experiment. Since the molecular mass of zirconia is larger than that of silica, the volume of zirconia filler is significantly smaller than that of silica at the same quality, which means that the specific surface area of zirconia is much smaller than that of silica, which may cause the resin composites containing a large proportion of zirconia to have better fluidity, suggesting resin composites with similar formulation were possible as a clinical resin cement. Furthermore, it is beneficial for high translucence ceramic restorations to bond with discolored teeth while in the dual-cured system. These resin materials containing an experimentally high proportion of nano-zirconia fillers have advantages for the bonding of ceramic restorations in which light cannot reach directly, such as the bonding of posts, inlays and endocrowns.

We next evaluated the biocompatibility of experimental nanohybrid composites for potential clinical applications via cytotoxicity testing. Here, we used groups with the highest flexural strength in light-cured and dual-cured groups (L-55Siz $+5 \mathrm{Mzr}$, L-55Si+5MZr, D-50Si+10Zr, and D-50Si+10MZr). The groups were used for the CCK-8 test to detect the proliferation of fibroblast L929. According to the current results, the cell proliferation rates of four resin material extracts after 5 days were $84.61 \%, 86.62 \%, 84.48 \%$, and $84.94 \%$. The cytotoxicity level was Grade 1 , according to the cytotoxicity grade standards, suggesting they are safe for clinical application due to the slight cytotoxicity. Based on previous studies, the monomer residues caused by the incomplete curing of resin composites such as Bis-GMA, TEGDMA, UDMA, and HEMA affect cell proliferation and thus interfere with the cellular redox system resulting in oxidative stress; thus, the cell cycle stagnates at a specific stage. ${ }^{39}$ In addition, resin materials present in the oral environment for the long term can be degraded by physical abrasion, chemical reactions and various enzymes; the degradation products likewise cause cytotoxicity. ${ }^{40}$

\section{Conclusion}

Based on results from the present study, and within its limitations, the null hypotheses can be rejected, and the following conclusions may be drawn: Adding nano-zirconia fillers improved the mechanical properties of resin composites, but it was not advisable to replace silica fillers as the main filler, because the resin composites with $5 \mathrm{wt} \%$ MDP-conditioned nano-zirconia exhibit the best mechanical property. When the content of the zirconia fillers reached $55 \mathrm{wt} \%$, the dual-cured system was essential for nanohybrid composites to be cured, which had a better opacity effect and met the ISO standard, making it potentially useful as a resin-luting cement. Adding MDP-conditioned zirconia fillers did not increase the cell cytotoxicity of nanohybrid composites.

\section{Acknowledgments}

The authors thank Mr Yan Fang (NIGPAS, China) for providing technical support in SEM observation. This work was supported by the National Natural Science Foundation of China [grant 81970927]; the Natural Science Foundation of Jiangsu Province of China [BK20191348]; the Qing Lan Project and the Priority Academic Program Development of Jiangsu Higher Education Institutions [grant 2018-87].

\section{Disclosure}

The authors report no conflicts of interest in this work.

\section{References}

1. Broadbent JM, Murray CM, Schwass DR, et al. The dental amalgam phasedown in New Zealand: A 20-year trend. Oper Dent. 2020;45 (3):255-264. doi:10.2341/19-024-C

2. Moraschini V, Fai CK, Alto RM, Santos GOD. Amalgam and resin composite longevity of posterior restorations: A systematic review and meta-analysis. $\quad J \quad$ Dent. $\quad 2015 ; 43(9): 1043-1050 . \quad$ doi:10.1016/j. jdent.2015.06.005

3. Beck F, Lettner S, Graf A, et al. Survival of direct resin restorations in posterior teeth within a 19-year period (1996-2015): A meta-analysis of prospective studies. Dent Mater. 2015;31(8):958-985. doi:10.1016/ j.dental.2015.05.004

4. Ástvaldsdóttir Á, Dagerhamn J, et al. Longevity of posterior resin composite restorations in adults - A systematic review. $J$ Dent. 2015;43(8):934-954. doi:10.1016/j.jdent.2015.05.001 
5. Habib E, Wang R, Wang Y, et al. Inorganic fillers for dental resin composites: present and future. ACS Biomater Sci Eng. 2016;2(1):111. doi:10.1021/acsbiomaterials.5b00401

6. Rodríguez HA, Kriven WM, Casanova H. Development of mechanical properties in dental resin composite: effect of filler size and filler aggregation state. Mater Sci Eng C Mater Biol Appl. 2019;101:274282. doi:10.1016/j.msec.2019.03.090

7. Wille S, Hölken I, Haidarschin G, Adelung R, Kern M. Biaxial flexural strength of new Bis-GMA/TEGDMA based composites with different fillers for dental applications. Dent Mater. 2016;32 (9):1073-1078. doi:10.1016/j.dental.2016.06.009

8. Karabela MM, Sideridou ID. Synthesis and study of properties of dental resin composites with different nanosilica particles size. Dent Mater. 2011;27(8):825-835.

9. Angerame D, Biasi MD. Do nanofilled/nanohybrid composites allow for better clinical performance of direct restorations than traditional microhybrid composites? A systematic review. Oper Dent. 2018;43 (4):E191-E209. doi:10.2341/17-212-L

10. Saen P, Atai M, Nodehi A, Solhi L. Physical characterization of unfilled and nanofilled dental resins: static versus dynamic mechanical properties. Dent Mater. 2016;32(8):e185-197. doi:10.1016/j.dental.2016.06.001

11. Wang R, Habib E, Zhu XX. Evaluation of the filler packing structures in dental resin composites: from theory to practice. Dent Mater. 2018;34(7):1014-1023. doi:10.1016/j.dental.2018.03.022

12. Lin G, Ghani N, Ismai N, et al. Fracture strength of endodontically treated lateral incisors restored with new zirconia reinforced rice husk nanohybrid composite. J Clin Exp Dent. 2020;12(8):e762-e770. doi: $10.4317 /$ jced. 56864

13. Wang R, Habib E, Zhu XX. Synthesis of wrinkled mesoporous silica and its reinforcing effect for dental resin composites. Dent Mater. 2017;33(10):1139-1148.

14. Habib E, Wang R, Zhu XX. Monodisperse silica-filled composite restoratives mechanical and light transmission properties. Dent Mater. 2017;33(3):280-287. doi:10.1016/j.dental.2016.12.008

15. Guo G, Fan Y, Zhang JF, Hagan J, Xu X. Novel dental composites reinforced with zirconia-silica ceramic nanofibers. Dent Mater. 2012;28(4):360-368. doi:10.1016/j.dental.2011.11.006

16. Kim S, Kim M, Shon M, Seo B, Lim C. Mechanical and thermal properties of epoxy composites containing zirconia-impregnated halloysite nanotubes with different loadings. J Nanosci Nanotechnol. 2018;18(9):6152-6156. doi:10.1166/jnn.2018.15610

17. Wu X, Dai S, Chen Y, He F, Xie H, Chen C. Reinforcement of dental resin composite via zirconium hydroxide coating and phosphate ester monomer conditioning of nano-zirconia fillers. J Mech Behav Biomed Mater. 2019;94:32-41. doi:10.1016/j.jmbbm.2019.03.002

18. Dai S, Chen Y, Yang J, He F, Chen C, Xie H. Surface treatment of nanozirconia fillers to strengthen dental bisphenol A-Glycidyl Methacrylate-based resin composites. Int $J$ Nanomedicine. 2019;14:9185-9197. doi:10.2147/IJN.S223392

19. Taczała J, Sawicki J, Pietrasik J. Chemical modification of cellulose microfibres to reinforce poly (methyl methacrylate) used for dental application. Materials. 2020;13(17):E3807. doi:10.3390/ma13173807

20. Nakanishi L, Kaizer MR, Brandeburski S, et al. Non-silicate nanoparticles for improved nanohybrid resin composites. Dent Mater. 2020;S0109-5641(20)30188-3.

21. Aydinoğlu A, Yoruç AH. Effects of silane-modified fillers on properties of dental composite resin. Mater Sci Eng C Mater Biol Appl. 2017;79:382-389. doi:10.1016/j.msec.2017.04.151

22. Koko M, Takagaki T, Abdou A, et al. Effects of the ratio of silane to 10methacryloyloxydecyl dihydrogenphosphate (MDP) in primer on bonding performance of silica-based and zirconia ceramics. J Mech Behav Biomed Mater. 2020;112:104026. doi:10.1016/j.jmbbm.2020.104026

23. Chen Y, Lu Z, Qian M, Zhang H, Xie H, Chen C. Effect of 10methacryloxydecyl dihydrogen phosphate concentration on chemical coupling of methacrylate resin to yttria-stabilized zirconia. $J$ Adhes Dent. 2017;19(4):349-355.
24. Qian M, Lu Z, Chen C, Zhang H, Xie H. Alkaline nanoparticle coatings improve resin bonding of 10-methacryloyloxydecyldihydrogenphosphate-conditioned zirconia. Int $J$ Nanomedicine. 2016;11:5057-5066. doi:10.2147/IJN.S116006

25. Yang J, Shen J, Wu X, He F, Xie H, Chen C. Effects of nano-zirconia fillers conditioned with phosphate ester monomers on the conversion and mechanical properties of Bis-GMA- and UDMA-based resin composites. J Dent. 2020;94:103306. doi:10.1016/j.jdent.2020.10 3306

26. Park CY, Choi B. Enhanced light extraction from bottom emission oleds by high refractive index nanoparticle scattering layer. Nanomaterials. 2019;9(9):1241. doi:10.3390/nano9091241

27. Shim JS, Kang JK, Jha N, Ryu JJ. Polymerization mode of selfadhesive, dual-cured dental resin cements light cured through various restorative materials. J Esthet Restor Dent. 2017;29(3):209-214. doi:10.1111/jerd.12285

28. Liu X, Wang Z, Zhao C, Bu W, Na H. Preparation and characterization of silane-modified $\mathrm{SiO}_{2}$ particles reinforced resin composites with fluorinated acrylate polymer. J Mech Behav Biomed Mater. 2018;80:11-19. doi:10.1016/j.jmbbm.2018.01.004

29. Moraes RR, Faria-e-Silva AL, et al. Impact of immediate and delayed light activation on self-polymerization of dual-cured dental resin luting agents. Acta Biomater. 2009;5(6):2095-2100. doi:10.1016/j. actbio.2009.01.030

30. Lian X, Wang C, Zhang K, Li L. The retrogradation properties of glutinous rice and buckwheat starches as observed with FTIR, 13C NMR and DSC. Int J Biol Macromol. 2014;64:288-293. doi:10.1016/ j.ijbiomac.2013.12.014

31. De-Paula DM, Loguercio AD, Reis A, et al. Micro-raman vibrational identification of 10-MDP bond to zirconia and shear bond strength analysis. Biomed Res Int. 2017;2017:8756396. doi:10.1155/2017/ 8756396

32. Adolphi B, Jähne E, Busch G, Cai X. Characterization of the adsorption of omega-(thiophene-3-ylalkyl) phosphonic acid on meta oxides with AR-XPS, Anal. Bioanal Chem. 2004;379:646-652. doi:10.1007/ s00216-004-2634-x

33. Rodrigues SA, Scherrer SS, Ferracane JL, Della Bona A. Microstructural characterization and fracture behavior of a microhybrid and a nanofill composite. Dent Mater. 2008;24(9):1281-1298. doi:10.1016/j.dental.2008.02.006

34. Goracci C, Cadenaro M, Fontanive L, et al. Polymerization efficiency and flexural strength of low-stress restorative composites. Dent Mater. 2014;30(6):688-694. doi:10.1016/j.dental.2014.03.006

35. Chen B, Lu Z, Meng H, et al. Effectiveness of pre-silanization in improving bond performance of universal adhesives or self-adhesive resin cements to silica-based ceramics: chemical and in vitro evidences. Dent Mater. 2019;35:543-553. doi:10.1016/j.dental.2019.01.010

36. Halder S, Ahmed S, Das S, Wang J. Epoxy/glass fiber laminated composites integrated with amino functionalized $\mathrm{ZrO}_{2}$ for advanced structural applications. ACS Appl Mater Interfaces. 2016;8(3):16951706. doi:10.1021/acsami.5b09149

37. Yoshihara K, Nagaoka N, Yoshida Y, Meerbeek BV, Hayakawa S. Atomic level observation and structural analysis of phosphoric-acid ester interaction at dentin. Acta Biomater. 2019;97:544-556. doi:10.1016/j.actbio.2019.08.029

38. Tian FC, Wang XY, Huang Q, et al. Effect of nanolayering of calcium salts of phosphoric acid ester monomers on the durability of resin-dentin bonds. Acta Biomater. 2016;38:190-200. doi:10.1016/j.actbio.2016.04. 034

39. Goldberg M. In vitro and in vivo studies on the toxicity of dental resin components: a review. Clin Oral Investig. 2008;12(1):1-8. doi:10.1007/s00784-007-0162-8

40. Salehi S, Gwinner F, Mitchell JC, Pfeifer C, Ferracane JL. Cytotoxicity of resin composites containing bioactive glass fillers. Dent Mater. 2015;31(2):195-203. doi:10.1016/j.dental.2014.12.004 


\section{Publish your work in this journal}

The International Journal of Nanomedicine is an international, peerreviewed journal focusing on the application of nanotechnology in diagnostics, therapeutics, and drug delivery systems throughout the biomedical field. This journal is indexed on PubMed Central, MedLine, CAS, SciSearch ${ }^{\mathbb{R}}$, Current Contents ${ }^{\mathbb{B}} /$ Clinical Medicine, $^{2}$
Journal Citation Reports/Science Edition, EMBase, Scopus and the Elsevier Bibliographic databases. The manuscript management system is completely online and includes a very quick and fair peer-review system, which is all easy to use. Visit http://www.dovepress.com/ testimonials.php to read real quotes from published authors.

Submit your manuscript here: https://www.dovepress.com/international-journal-of-nanomedicine-journal 